\title{
Natural Fibres as Reinforcement Strategy on Cork-Polymer Composites
}

\author{
Emanuel M. Fernandes ${ }^{1,2, a}$, Vitor M. Correlo ${ }^{1,2, b}$, João F. Mano ${ }^{1,2, c}$ \\ and Rui L. Reis ${ }^{1,2, d}$
}

\author{
13B's Research Group - Biomaterials, Biodegradables and Biomimetics, Department of Polymer \\ Engineering, University of Minho, AvePark, Zona Industrial da Gandra, S. Cláudio do Barco, 4806- \\ 909 Caldas das Taipas - Guimarães, Portugal \\ ${ }^{2}$ ICVS/3B's - PT Government Associate Laboratory, Braga/Guimarães, Portugal \\ aefernandes@dep.uminho.pt, ${ }^{b}$ vitorcorrelo@dep.uminho.pt, cjmano@dep.uminho.pt, \\ 'rgreis@dep.uminho.pt
}

Keywords: Cork composites; Natural fibres; Mechanical properties; Morphology.

\begin{abstract}
Cork powder, the most important sub-product of cork processing, combined with thermoplastic matrixes like, high density polyethylene (HDPE), offer a new class of cork-polymer composite (CPC) materials with high added-value. Therefore, reinforcing strategies must be considered to increase the mechanical performance, especially when high content of cork powder is added to the formulation. Coconut fibres have several advantages, such as, low density, renewable source, low cost and biodegradability. The use of these fibres on the reinforcement of CPC materials will not only contribute to improve the mechanical performance but also for increasing the amount of natural component present on the final composition. The main goal of this work was to prepare HDPE/cork (50-50 wt.\%) composites reinforced with discontinuous coconut fibres (5 and $10 \mathrm{wt} . \%$ ) with and without the addition of coupling agent ( $2 \mathrm{wt} . \%)$ by extrusion. The developed reinforced cork based composites were characterized regarding its morphology and mechanical performance. Optical micrographs have shown a homogeneous distribution of the fibres. The coupling agent effect on CPC performance was also investigated. The tensile strength and tensile modulus of the reinforced composites were significantly improved with the addition of coupling agent. The use of $10 \mathrm{wt} . \%$ of coconut fibres in the presence of coupling agent promote an increase on maximum tensile strength of around $41 \%$ comparing with the HDPE/cork (50-50 wt.\%) composites. Scanning electron microscopy (SEM) micrographs of the tensile fractured specimens confirmed that the use of coupling agent promoted the interfacial adhesion between the fibres and the thermoplastic matrix. Since, like cork powder, coconut fibres have good thermal and acoustic properties, we consider that the novel reinforced CPC herein described have high potential to be used in building and construction systems and other structural 3D applications.
\end{abstract}

\section{Introduction}

Cork is the outer bark of the cork oak tree, botanically knew as Quercus suber L. [1]. It is a natural foamed material with closed cell structure, presenting an anisotropic structure, low density, hydrophobic behaviour comparing with wood based materials, excellent performance as thermal and acoustic insulator, interesting antivibratic properties, a near zero Poisson coefficient and low thermal conductivity. The combination of these properties makes of cork a material of choice for several applications including, as sealant material, thermal and acoustic insulator, flooring or in combination with rubber for gaskets in the automotive [1,2]. Cork composites are one of the most promising fields under development on cork industry [3]. Previous works have shown the potential of combining this lightweight material with polyolefin's through melt based technologies [4, 5], in order to create a profitable alternative to the storage or burning of the sub-products, such as the cork powders, obtained from several ending stages of cork industry. However, the use of high percentage of this natural material (e.g. 50 wt.\%) represents a high volume content and consequently a reduction on the mechanical performance of the final composite material. Some of the routes used 
to improve the interfacial adhesion between cork and the polymeric matrix and, consequently the mechanical performance, includes the use of coupling agents [4], optimization of the processing conditions [7], use of natural origin fibres [8] and fibre modification [6].

The advantages of natural fibres are its low cost, low density, specific strength, good thermal insulation properties, reduced tool wear, renewable resource and recyclable. Several natural fibres based thermoplastic composites have already found applications in furniture, packaging, building and automobile industries [9]. Additionally, cellulosic fibres like coconut fibres have higher modulus when compared to thermoplastic materials. Thus, these types of fibres can be strategically used to improve the strength and stiffness of composite $[9,10]$.

Polymer, cork and natural fibres are not easily compatibilzed, although some polymers are more compatible than others providing better bonding interface. In the literature is reported that the natural waxy surface layer of coconut fibres provides a strong interfacial bonding between the fibres and the polyethylene matrix, due to its polymeric nature [11]. In this study, the coconut fibres were analysed regarding its thermal stability using thermogravimetric analysis (TGA). The contribution of coconut fibres for the improvement of composite mechanical properties was evaluated by uniaxial tensile tests. The tensile fracture surface of the different compositions was analysed by scanning electron microscopy (SEM). According to the present work the mechanical properties of the cork-polymer composites (50-50 wt.\%) increased with the addition of short coconut fibres, preferably with the use of a coupling agent based on maleic anhydride.

\section{Materials and Methods}

In the present study was used a commercially available high density polyethylene (HMA - 025), HDPE, with the following properties: a melting point of $136.6^{\circ} \mathrm{C}$ and MFI of $8 \mathrm{~g} 10 \mathrm{~min}^{-1}$ (Exxon Mobil, Germany). The cork powder resulting from the sanding process, with a particle size < $500 \mu \mathrm{m}$ and density of $157 \pm 2 \mathrm{~kg} \mathrm{~m}^{-3}$, was supplied by Amorim Revestimentos, S.A. (Portugal). The brown coconut fibres, with an average diameter of $277.4 \pm 38.8 \mu \mathrm{m}$ and a density of $845 \pm 46$ $\mathrm{kg} \mathrm{m}^{-3}$, were kindly provide by Amorim Isolamentos, S.A.(Portugal). The coupling agent used was based on maleic anhydride $102-1$ K1 MDEX (A. Schulman GmbH, Germany).

The cork powder and the coconut fibres were dried overnight, at $80^{\circ} \mathrm{C}$, to reduce the moisture content. The different compositions were compounded on a counter-rotating twin screw extruder (Carvex, Portugal) with a temperature profile between 130 and $155^{\circ} \mathrm{C}$ and a screw speed of $30 \mathrm{rpm}$. The raw materials (HDPE and cork powder) were used in the powder form and all the coconut fibres had a size smaller than $20 \mathrm{~mm}$. Before extrusion all the components were premixed in the appropriate ratios according to the formulations listed in Table 1. The composites, as pellets with a length smaller than $5 \mathrm{~mm}$, were further compression-moulded using a hydraulic press (Moore, UK) using the following conditions: temperature: $150{ }^{\circ} \mathrm{C}$ during a period of $8 \mathrm{~min}$ plus $2 \mathrm{~min}$ under pressure: $1.42 \mathrm{MPa}$. Samples of $3 \mathrm{~mm}$ thick were prepared and further used to obtain tensile specimens as described in our previous work [4].

Table 1: Formulations of the reinforced cork-polymer composites.

\begin{tabular}{|l|l|l|l|l|}
\hline Sample Code & $\begin{array}{l}\text { HDPE + Cork } \\
(\text { wt. } \%)\end{array}$ & $\begin{array}{l}\text { Coconut Fibre } \\
(\text { wt. } \%)\end{array}$ & $\begin{array}{l}\text { Coupling Agent } \\
(\text { wt.\%) }\end{array}$ & $\begin{array}{l}\text { Natural Component } \\
\text { (wt. \%) }\end{array}$ \\
\hline CPC $(50-50)$ & $50-50$ & 0 & 0 & 50 \\
\hline CPC $+5 \%$ CF & $50-50$ & 5 & 0 & 53.5 \\
\hline CPC $+5 \%$ CF + MA & $50-50$ & 5 & 2 & 52.5 \\
\hline CPC $+10 \%$ CF & $50-50$ & 10 & 0 & 55 \\
\hline CPC $+10 \%$ CF + MA & $50-50$ & 10 & 2 & 54 \\
\hline
\end{tabular}

Thermal gravimetric analyses (TGA) were also conducted (TGA Q500, TA Instrument). The samples were heated from $50{ }^{\circ} \mathrm{C}$ to $600{ }^{\circ} \mathrm{C}$ at $10{ }^{\circ} \mathrm{C} / \mathrm{min}$ in air medium. Analysis was performed two times for each sample. 
The fracture surface of the reinforced cork polymer composites was analysed using a NanoSEM 200 FEI (The Netherlands) scanning electron microscope (SEM). All the samples were previously coated by ion sputtering with an $\mathrm{Au} / \mathrm{Pd}$ alloy (80-20 wt.\%) in a high resolution sputter coater of Cressington 208HR (Watford, UK).

Tensile properties of the developed composites were determined using an Instron 4505 Universal Machine (USA) equipped with a cell load of $1 \mathrm{kN}$. The crosshead speed was $5 \mathrm{~mm} / \mathrm{min}$. Height specimens per condition were tested until break. Tensile bars had a neck cross-section area of $3 \mathrm{~mm} \times 4 \mathrm{~mm}$ and a gage length of $20 \mathrm{~mm}$. Even its thickness is slightly higher $(3 \mathrm{~mm})$ than the standard; the specimens were produced according ASTM D 638-03. Tensile modulus was determined at 0.05 to $0.25 \%$ of deformation using a linear regression.

\section{Results and Discussion}

The thermogravimetric analyses of both natural materials were conducted on air aiming to evaluate its thermal stability and the weight loss results are reported in Fig. 1. For both, cork powder and the coconut fibres, no significant changes were observed in terms of weight loss for temperatures below $200{ }^{\circ} \mathrm{C}$. Just around $100{ }^{\circ} \mathrm{C}$ a slight decrease was observed, corresponding, as expected, to the release of humidity from the fibres.
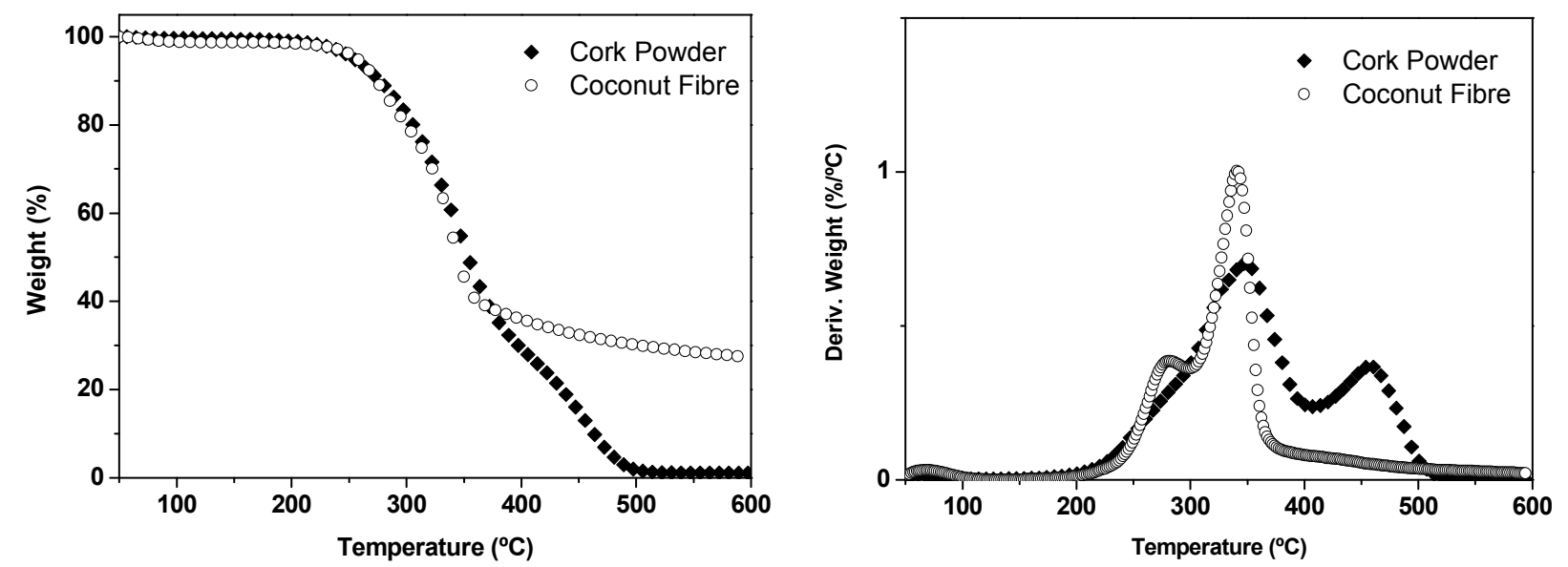

Fig.1. Thermogravimetric analysis of the natural materials.

For temperatures higher than $200^{\circ} \mathrm{C}$, the coconut fibres have shown better thermal stability. From the derivative curves it is possible to observe that coconut fibre have two degradation temperatures, at $282{ }^{\circ} \mathrm{C}$ and $341{ }^{\circ} \mathrm{C}$, corresponding to the degradation of chemical components present on its composition. In the case of the cork powder, the degradation occurs also in two stages but at higher temperatures: $348^{\circ} \mathrm{C}$ and $458^{\circ} \mathrm{C}$, respectively.
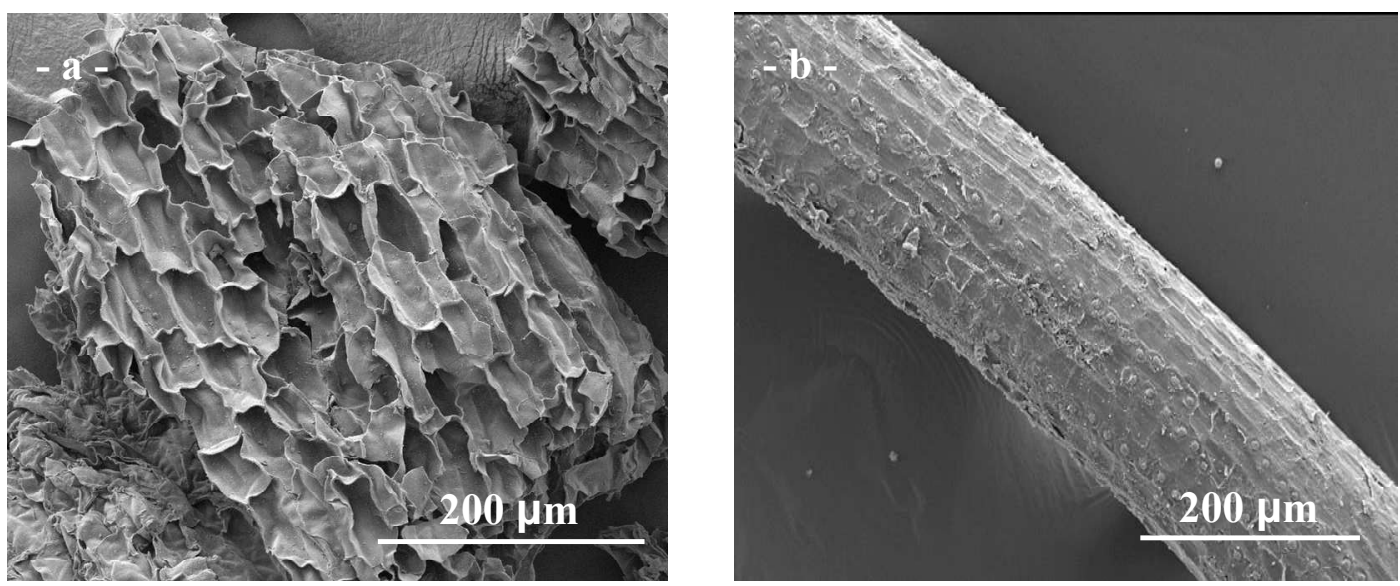

Fig. 2. SEM micrographs showing the morphology: a) cork powder and b) coconut fibre. 
These results suggest that the chemical structure of cork has components with higher thermal stability compared with the ones present on coconut fibres. Nevertheless, for both cases, these temperatures are much higher than the higher processing temperature used on preparation of the composites: less than $160^{\circ} \mathrm{C}$.

On Fig. 2 are shown SEM micrographs corresponding to the morphology of both natural components. From Fig. 2 a) it is possible to observe the typical morphology of a cork granule $(<$ $500 \mu \mathrm{m}$ ) including the cellular structure with closed cells and the high amount of available cells in a small area. In Fig. 2 b) is shown the typical surface of a coconut fibre with a diameter of $\sim 200 \mu \mathrm{m}$. The fracture surfaces, after mechanical testing, of the prepared composites were analyzed by SEM and the results are shown in Fig. 3.
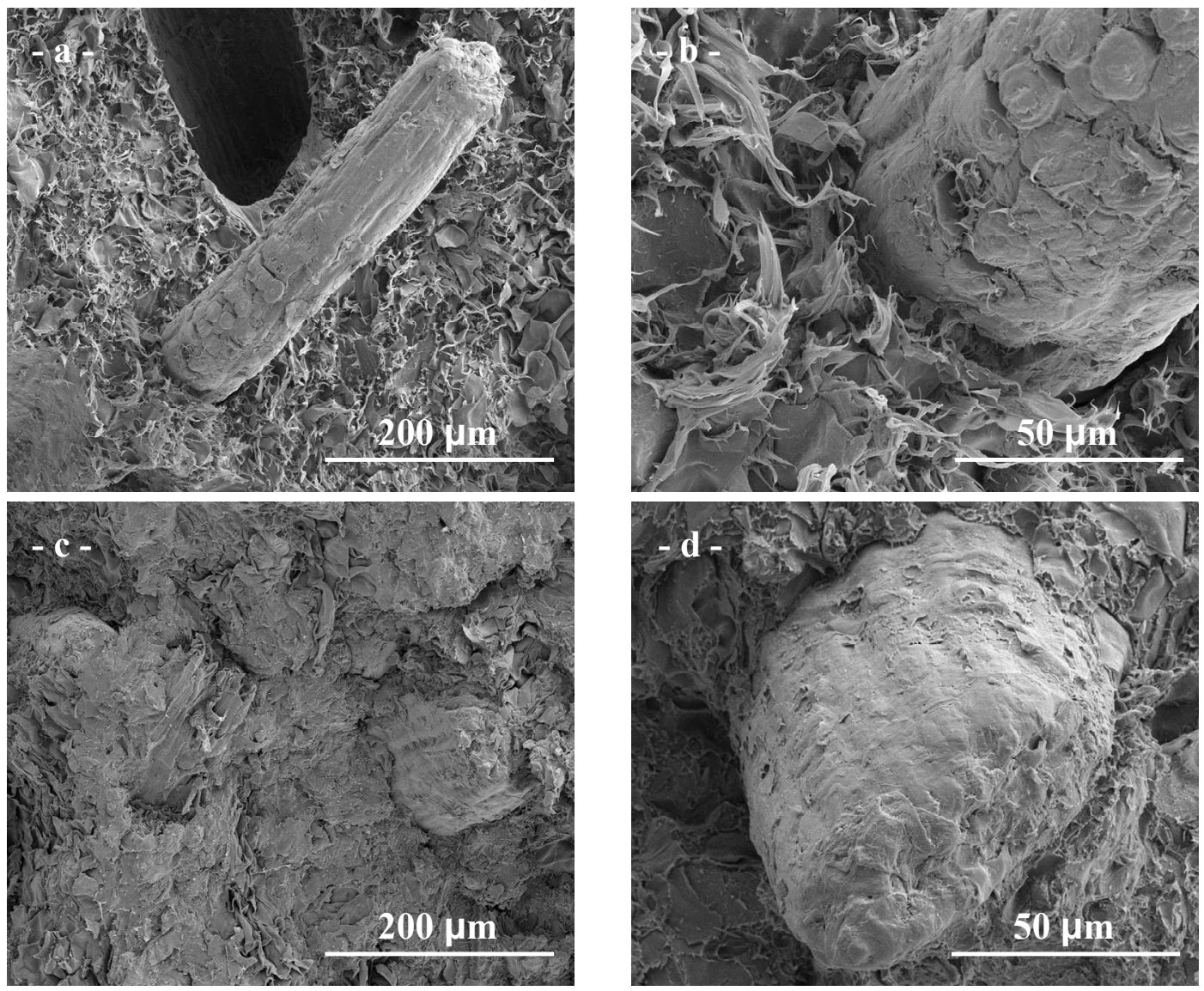

Fig. 3. SEM micrographs showing the fracture morphology of the developed cork-polymer composites reinforced with 5 wt.\% of coconut fibre: $(a, b)$ without coupling agent and (c, d) with 2 wt.\% of coupling agent.

SEM micrographs from the fracture surface morphology of the different composites obtained after tensile tests are shown in Fig. 3. In Fig. 3 a) is possible to observe the pull-out of a coconut fibre. At high magnifications (Fig 3b) a small gap between the coconut fibre and the cork-polymer phase was noticed. Both conditions indicate the lower adhesion of the coconut fibre to the polymeric matrix.

Fig 3 c) and d) presents the fracture of the previous system in the presence of $2 \mathrm{wt} . \%$ of coupling agent based on maleic anhydride. In this case was not observed the stretch of the polymeric phase and the fracture of the fibre occur at the same plane of the surface fracture. Moreover it was observed an improved adhesion between the coconut fibre and the cork-polymer phase. 

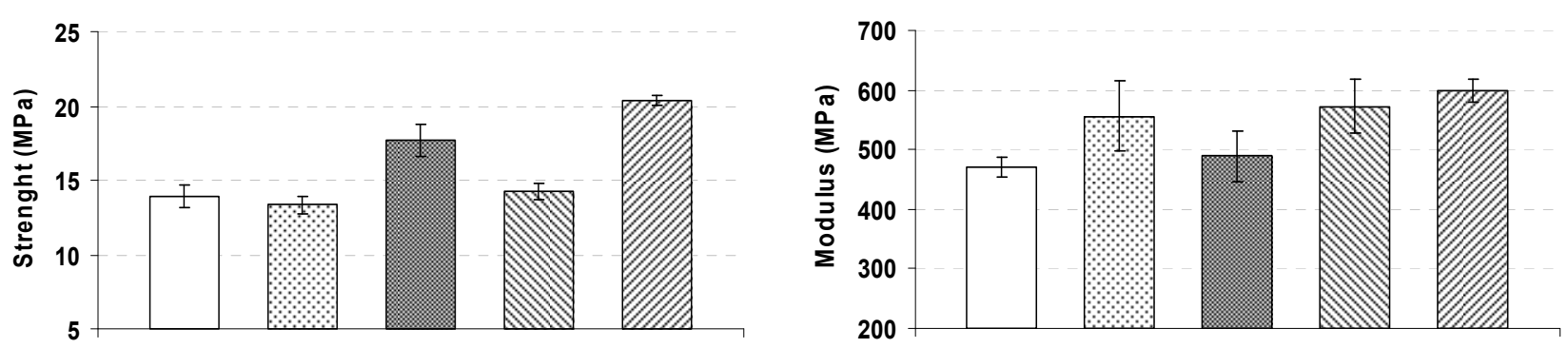

$\square \mathrm{CPC}(50 \%-50 \%) \quad \mathrm{CPC}+5 \% \mathrm{CF}$ - $\mathrm{CPC}+5 \% \mathrm{CF}+\mathrm{MA} \otimes \mathrm{CPC}+10 \% \mathrm{CF}$

$\square C P C+10 \% C F+M A$

Fig. 4. Mechanical properties of the cork-polymer composites (50-50 wt.\%) and the reinforced composites with coconut fibre with or without $2 \mathrm{wt} . \%$ of coupling agent.

The tensile properties, tensile strength and tensile modulus, of the different composite formulations are presented in Fig. 4. It was not observed a significant improvement of the tensile strength of the composites when coconut fibres where incorporated in both ratios of $5 \mathrm{wt} . \%$ or 10 $\mathrm{wt} \%$. However, a clear increase in the stiffness was noticed. Moreover, when $2 \mathrm{wt} \%$ of maleic anhydride was used, it was observed a significant increase that was proportional to the amount of coconut fibres added. The use of $10 \mathrm{wt} \%$ of coconut fibre with coupling agent, improved the tensile strength in $41 \%$. In the presence of coupling agent and in terms of modulus an improvement was observed for the 5 and $10 \mathrm{wt} . \%$ of coconut fibre. In the last case an improvement of $27 \%$ in stiffness occurred.

Comparing with a previous work, where it was used pultrusion and compression moulding to produce cork-polymer composites [4], the use of the coupling agent based on maleic anhydride promoted an improvement of around $10.3 \%$ in strength of the composites prepared using a the same grade of high density polyethylene as matrix.

Literature reported the use of this methodology for other lignocellulosic fibres like wood, where the use of compatibilizers, such as functionalized polyolefin's, were incorporated to lower the interfacial tension between the polyethylene matrix and wood filler $[12,13]$. In the present work the improvement of the mechanical properties of the developed composites in the presence of short coconut fibres and coupling agent are in accordance with the morphological tensile fracture observations.

\section{Conclusions}

The developed cork-polymer composites reinforced with natural origin fibres presents improved mechanical properties with an increase of the natural component on the composite. The use of 10 wt.\% of coconut fibres in the presence of low amount of coupling agent based on maleic anhydride improved the strength in $41 \%$ and the stiffness in $27 \%$ comparing with the cork-polymer composite (50-50) wt.\%. The morphology of the composites reveals that the coupling agent based on maleic anydride play an important role in terms of adhesion between the matrix and the natural fibres. The novel cork-polymer composites reinforced with natural fibres proposed on this work shows that this technological approach can be industrially appealing.

Acknowledgements: The authors acknowledge to Corticeira Amorim S.G.P.S. (Portugal) on the development of new products based in/with cork and for the supply of cork powder material and to Amorim Isolamentos, S.A. (Portugal) the coconut fibres. To QREN FCOMP-01-0202-FEDER003107 financing support on the project "NovelComp". E.M. Fernandes and V.M. Correlo acknowledges to Portuguese Foundation for Science and Technology (FCT) grants (SFRH/BD/71561/2010) and (SFRH/BPD/64790/2009) respectively. 


\section{References}

[1] H. Pereira, Cork: biology, production and uses, 1st edn., Amsterdam: Elsevier, 2007.

[2] S.P. Silva, M.A. Sabino, E.M. Fernandes, V.M. Correlo, L.F. Boesel, R.L. Reis, Cork: properties, capabilities and applications, Int Mater Rev. 50(6) (2005) 345-365.

[3] L. Gil, Cork composites: A review, 2 (3) Mater. (2009) 776-789.

[4] E.M. Fernandes, V.M. Correlo, J.A.M. Chagas, J.F. Mano, R.L. Reis, Cork based composites using polyolefin's as matrix: Morphology and mechanical performance, Compos Sci Technol. 70 (2010) 2310-2318.

[5] E.M. Fernandes, V.M. Correlo, J.A.M. Chagas, J.F. Mano, R.L. Reis, Properties of new cork-polymer composites: Advantages and drawbacks as compared with commercially available fibreboard materials. Compos Struct. 93(12) (2011) 3120-3129.

[6] F.B. Abdallah, R.B. Cheick, M. Baklouti, Z. Denchev, A.M. Cunha, Effect of surface treatment in cork reinforced composites. J. Polym. Res. 17 (4) (2010) 519-528.

[7] E.M. Fernandes, V.M. Correlo, J.F. Mano, R.L. Reis, Cork based composites as core in flooring applications: Characterization and optimization process using experimental design, 2nd IBB Scientific Meeting, Braga, Portugal, 2010.

[8] E.M. Fernandes, V.M. Correlo, J.A.M. Chagas, R.L. Reis, PCT Patent WO2011/014085-A2. (2011).

[9] A.K. Bledzki, J.Gassan, Composites reinforced with cellulose fibres, Prog. Polym. Sci. 24 (1999) 221-74.

[10] N.G.J.-Smith, G. Virgo, V.E. Buchanan, Potential of Jamaican banana, coconut coir and bagasse fibres as composite materials, Mater. Charact. 59 (2008) 1273-1278.

[11] M. Brahmakumar, C. Pavithran, R.M. Pillai, Coconut fibre reinforced polyethylene composites: effect of natural waxy surface layer of the fibre on fibre/matrix, Compos. Sci. Technol. 65 (2005) 563-569.

[12] S.-M. Lai, F.-C. Yeh, Y. Wang, H.-C. Chan, H.-F. Shen, Comparative study of maleated polyolefins as compatibilizers for polyethylene/wood flour, composites, J. Appl. Polym. Sci. 87 (2003) 487-496.

[13] TJ Keener, RK Stuart, TK Brown. Maleated coupling agents for natural fibre composites. Compos Part A-Appl S. 35(3) (2004) 357-362. 